\title{
Presymptomatic testing for autosomal dominant spinocerebellar ataxia type 1
}

\author{
A E Shrimpton, Rosemary Davidson, N MacDonald, D J H Brock
}

\begin{abstract}
Presymptomatic cesting was done on four people from a large family in which an autosomal dominant form of spinocerebellar ataxia was segregating. Earlier genetic analysis had shown that in this family the disorder was tightly linked to an informative microsatellite polymorphism on chromosome $6 \mathrm{p}$. Two subjects with prior risks of $50 \%$ of developing the disease had final risks after testing of $2 \%$; the other two with prior risks of $25 \%$ had final risks of $1 \%$. Chromosome 6p linked spinocerebellar ataxia may now be added to Huntington's disease as a late onset disorder in which genetic linkage may be used to carry out presymptomatic testing.

(f Med Genet 1993;30:616-17)
\end{abstract}

The inherited spinocerebellar ataxias are progressive neurological disorders characterised by degeneration of cerebellum, spinal cord, and brain stem. They are clinically and genetically heterogeneous. ${ }^{1}$ Among the dominantly inherited forms is a subtype, SCA1, which has been linked to the short arm of chromosome 6, near to the HLA locus. ${ }^{2-5}$ Subjects with SCA1 have progressive ataxia of gait, dysarthria, and dysphagia. Age at onset of symptoms is between 20 and 50 years. The disease progresses over several decades, ultimately resulting in death. ${ }^{6}$

Not all types of dominantly inherited spinocerebellar ataxia are linked to chromosome $6 .^{78}$ Thus before using genetic markers to track the SCAl gene through at risk families, it is necessary to carry out a formal linkage analysis of cosegregation of gene and marker within that family. This requires a large family and a highly informative marker. Recently, a dinucleotide repeat polymorphism with multiple alleles at the D6S89 locus $^{9}$ has been shown to

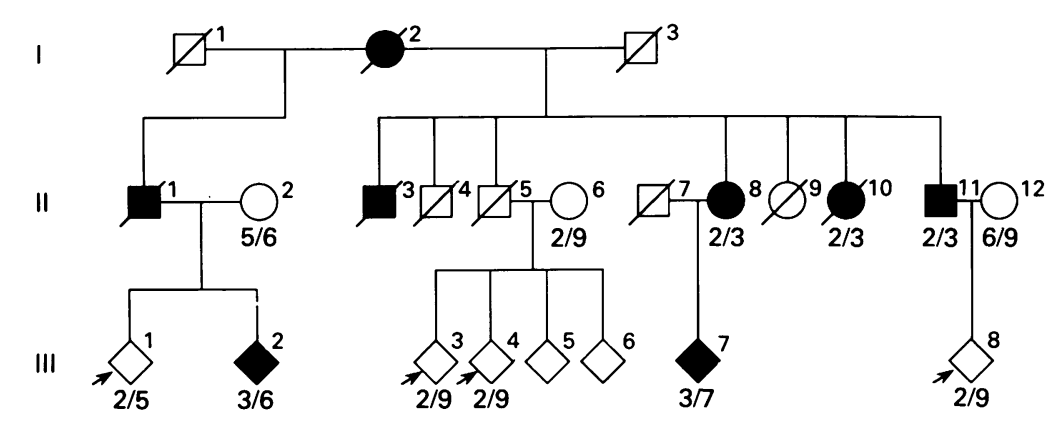

Pedigree of the family in which SCA1 is segregating. Affected people are shaded and probands arrowed. Genotypes at the D6S89 locus are shown beneath the pedigree symbols.

\section{University of \\ A E Shrimpton \\ Duncan Guthrie \\ Institute of Medical \\ Glasgow, UK. \\ The Surgery, Tarbert, \\ Loch \\ N MacDonald \\ Correspondence to Professor Brock. \\ Received 16 October 1992 Revised version accepted 7 January 1993.}

be tightly linked to SCA1..$^{10-12}$ This system is useful not only for confirming linkage within a family but also for using in presymptomatic testing.

Part of an extended Scottish family (family 2 in reference 1) with SCA1 is shown in the figure. The mean age of onset of disease was 39 years. Testing for D6S89 alleles in DNA samples from nine affected and 50 unaffected members gave a maximum lod score of 3.4 at $\theta=0$, representing odds of $2500: 1$ that the marker and SCA1 are genetically linked in this family. ${ }^{13}$

Four subjects (arrowed in the figure; sexes concealed for reasons of confidentiality), who had no signs of SCA1 at ages $30,33,36$, and 52 , requested presymptomatic testing. Two (III.1 and III.8) had affected parents and a $50 \%$ prior risk (unadjusted for age). The other two (III.3 and III.4) had a father who had died of other causes at a comparatively early age and who were therefore at $25 \%$ risk. All four went through a genetic counselling protocol similar to that used in preclinical testing for Huntington's disease. ${ }^{14}$

D6S89 genotypes were determined after polymerase chain reaction amplification by methods previously described. ${ }^{9}$ Inspection of the pedigree shows that allele 3 is in phase with the SCA1 gene, and that none of the four probands had inherited this allele. Thus each had their prior risk substantially reduced. The exact residual risk depends on assumptions made about the recombination rate between the D6S89 and SCA1 loci. At a recombination fraction of 5\%," III.1 and III.8 have a residual risk of developing SCA1 of $5 \%$, while for III. 3 and III. 4 it is $2.5 \%$. At the more likely recombination fraction of $2 \%^{1213}$ the figures are $2 \%$ and $1 \%$, respectively.

Presymptomatic testing for late onset autosomal dominant disorders has to date been largely confined to Huntington's disease. This is a genetically homogeneous entity with invariably severe outcome. A battery of polymorphic markers on chromosome $4 p$ permits a reasonable estimate of the residual risk of developing the disease after DNA testing. However, since the prospects for those found to carry the gene are so gloomy, it is essential that pre-test counselling be carried out according to internationally agreed protocols. ${ }^{15}$ The same imperative applies to the dominantly inherited ataxias, but with the additional requirement that a prior linkage analysis be carried out in the family at risk.

This study was supported by grants from the Ludovici Bequest to the University of Edinburgh. 
1 Harding AE. The clinical features and classifications of the late onset autosomal dominant cerebellar ataxias. Brain 1982;105:1-28.

2 Yakura H, Wakisaka A, Fujimoto S, Itakura K. Hereditary ataxia and HLA genotypes. $N$ Engl $\mathcal{F}$ Med 1974;291:154 5.

3 Jackson JF, Currier RD, Terasaki PI, Morton NE. Spinocerebellar ataxia and HLA linkage. $N$ Engl $\mathcal{f} \mathrm{Med}$ 1977;296:1138-41.

4 Morton NE, Lalouel JM, Jackson JF, Currier RD, Yee S. Linkage studies in spinocerebellar ataxia (SCA). $A m \mathcal{F}$ Med Genet 1980;6:251-7.

5 Pederson L, Platz P, Ryder LP, Lamm LU, Dissing J. A linkage study of hereditary ataxias and related disorders: evidence of heterogeneity of dominant cerebellar ataxia. Hum Genet 1980;54:371-83.

6 Haines Jenet Schut LJ, Weitkamp LR, Thayer M, Anderson VE. Spinocerebellar ataxia in a large kindred: age at onset, reproduction, and genetic linkage studies. Neurology reproduction, and

7 Auburger G, Diaz GO, Capote RF, et al. Autosomal dominant ataxia: genetic evidence for locus heterogeneity from a Cuban founder-effect population. $\mathrm{Am} \mathcal{F} \mathrm{Hum}$ Genet 1990;46:1163-77.

8 Ranum LPW, Rich SS, Nance WA, et al. Autosomal dominant spinocerebellar ataxia: locus heterogeneity in a Nebraska kindred. Neurology 1992;42:344-7.
9 Litt M, Luty JA. A TG microsatellite VNTR detected by PCR is located on 6p (HGM10 No D6S89). Nucleic Acids Res 1990;18:4301.

10 Keats BJB, Polack MS, McCall A, et al. Tight linkage of the gene for spinocerebellar ataxia to D6S89 on the short arm of chromosome 6 in a kindred for which close linkage to both HLA and F13Al is excluded. Am $\mathcal{f}$ Hum Genet 1991;49:972-7.

11 Zoghbi HY, Jodice C, Sandkuijl LA, et al. The gene for autosomal dominant spinocerebellar ataxia (SCA1) maps telomeric to the HLA complex and is closely linked to the D6S89 locus in three large kindreds. Am f Hum Genet 1991;49:23-30.

12 Ranum LPW, Duvick LA, Rich SS, Schut LJ, Litt M, Orr HT. Localization of the autosomal dominant HLA-linked spinocerebellar ataxia (SCA1) locus, in two kindreds, within an 8-cM subregion of chromosome 6p. Am $\mathrm{F} \mathrm{Hum}$ Within an 8-cM subre

13 Shrimpton AE, Blackwood D, Vijayalaxmi, et al. Dominantly-inherited spinocerebellar ataxia (SCA1): linkage studies. F Med Genet 1992;29:278-9.

14 Brock DJH, Mennie M, Curtis A, et al. Predictive testing for Huntington's disease with linked markers. Lancet 1989;ii:463-6.

15 Harper PS, Morris MJ, Tyler A. Genetic testing for Huntington's disease: internationally agreed guidelines are being followed. $B M \mathcal{A}$ 1990;300:1089-90. 